\title{
Techno-Economic Analysis and New Design of a Photovoltaic Power Plant by a Direct Radiation Amplification System
}

\author{
Hamed Khodayar Sahebi ${ }^{1}$, Siamak Hoseinzadeh ${ }^{2, *} \mathbb{D}$, Hossein Ghadamian ${ }^{3}$, Mohammad Hadi Ghasemi ${ }^{4}$, \\ Farbod Esmaeilion ${ }^{5}$ (D) and Davide Astiaso Garcia ${ }^{2}$ (D) \\ 1 Department of Energy, Materials and Energy Research Center (MERC), Karaj 31779-83634, Iran; \\ H.khodayar@merc.ac.ir \\ 2 Department of Planning, Design, and Technology of Architecture, Sapienza University of Rome, \\ Via Flaminia 72, 00196 Rome, Italy; davide.astiasogarcia@uniroma1.it \\ 3 Department of Energy, Materials and Energy Research Center (MERC), Tehran 15169-53715, Iran; \\ h.ghadamian@merc.ac.ir \\ 4 Persian Namad Mehr Engineering, Tehran 19319-13853, Iran; hadi.ghasemi71@gmail.com \\ 5 Department of Mechanical Engineering, K.N. Toosi University of Technology, Tehran 19967-15433, Iran; \\ farbodesmailion@gmail.com \\ * Correspondence: siamak.hosseinzadeh@uniroma1.it
}

Citation: Khodayar Sahebi, H.; Hoseinzadeh, S.; Ghadamian, H.; Ghasemi, M.H.; Esmaeilion, F.; Garcia, D.A. Techno-Economic Analysis and New Design of a Photovoltaic Power Plant by a Direct Radiation Amplification System. Sustainability 2021, 13, 11493. https://doi.org/ $10.3390 /$ su132011493

Academic Editors: Maurice B.

Dusseault, SeyedBijan Mahbaz and Alireza Dehghani-Sanij

Received: 16 September 2021

Accepted: 7 October 2021

Published: 18 October 2021

Publisher's Note: MDPI stays neutral with regard to jurisdictional claims in published maps and institutional affiliations.

Copyright: (c) 2021 by the authors. Licensee MDPI, Basel, Switzerland. This article is an open access article distributed under the terms and conditions of the Creative Commons Attribution (CC BY) license (https:/ / creativecommons.org/licenses/by/ $4.0 /)$.

\begin{abstract}
Today, photovoltaic panels are used in various applications, and increasing their efficiency is of interest to many researchers. In this research, we try to increase the radiation density by increasing direct radiation to finally increase the energy production in photovoltaic power plants. The direct radiation amplification system is used to improve the photovoltaic efficiency. In this proposed system, energy and economics are analyzed by MATLAB software. Also, prototype testing and photovoltaic power plant testing are examined. The results show that by implementing this system in photovoltaic power plants, annual energy production can be increased. By adding this system to a photovoltaic power plant, the price of electricity produced in photovoltaic power plants will be increased from $13 \not / k W h$ to $9 \notin / k W h$, which shows a $31 \%$ reduction in the price of electricity per kilowatt-hour.
\end{abstract}

Keywords: direct radiation amplification system; photovoltaic; solar energy

\section{Introduction}

Nowadays, the technology developments and substantial growth of clean energy supply for various purposes through the expansion and use of renewable energy systems have become unavoidable [1-3]. In the meantime, solar energy has been introduced as a privileged source to drive energy systems. There exist two leading facilities that convert solar energy to electrical power, photovoltaic (PV) systems and concentrated solar power (CSP).

During the decade from 2006 to 2016, the global capacity of PV systems improved by 293 GW (from 7 GW to 300) [4]. Moreover, the number of small-scale and utility-scale PV systems, for residential and industrial applications, increased considerably [5]. It should be highlighted that the proper price discount of PV technology and the advent of economic motivation strategies like feed-in tariffs and net metering were the main reasons for this trend [6]. From the economic point of view, the PV modules dominated the overall cost of PV installations. While this value is around $35-40 \%$ of the overall investment expenditures [7]. An advanced penetration of solar is in a weak position because of fluctuations of the energy generated, which springs from the natural inconsistency of the solar energy supply. A portion of this variation is affected by stochastic atmospheric processes such as cloud formation and the modeling of PV facilities mostly becomes complicated and the calculated values for some parameters turn uncertain [8-10]. Improvements in the powerful simulations are required to reduce the rate of uncertainty $[11,12]$. 
Accurate simulations, proper methodologies for system analysis, and periodic monitoring are the practical methods to study PV systems. Yield calculations are necessary for feasibility investigations to select the optimal locations and calculate approximately the economic risks of the investments [13,14]. In this case, it should be noted that the simulation of PV technologies is classified as the energy rating including a presence of comparison among the real operational parameters of various modules under the standard conditions. This type of simulation studies the performance ratio of different PV systems under diverse climatic settings $[15,16]$. By the simulation procedures for yield estimation, all detailed data of the system, like power losses and the number of solar radiations at the considered location (containing shading effects, soiling impacts, and snow setbacks), become accessible. On the other hand, energy rating models are not dependent on these factors. Consequently, irradiation details are more important for yield calculations, while that is not the individual and dominant element [17]. Nonetheless, it is considered for about $50 \%$ of the total uncertainty $[18,19]$. The ground measurements have the highest accuracy of irradiation data for PV models [20]. Nonetheless, ground sensors are sporadically scattered and infrequently near the PV system site. Many analyses have been performed in the field of thermal optimization of energy production systems with photovoltaic panels. These analyses include energy exergy analysis of heat collectors and photovoltaic panels, which increase the production capacity as well as the exergy efficiency [21-24].

Meanwhile, the combination of economical parameters with the technical factors can present a comprehensive approach to investigating the PV modules more accurately. This technique of analysis will improve the results of PV simulation and analysis obtained two fold while the economic feasibilities and technical accessibilities can be examined. Therefore, various types of methodology for techno-economic analysis have been introduced. Hiendro et al. [25] put forward a techno-economic study of PV-wind hybrid systems for onshore and remote areas. In this study, HOMER software was employed to conduct the techno-economic study. Based on the results, a PV panel could generate power equal to $2079 \mathrm{~kW} /$ year. Moreover, the levelised cost of electricity (LCOE) for this hybrid system was $0.751 \mathrm{US} \$ / \mathrm{kWh}$. Ashtiani et al. [26] conducted a techno-economic study for a gridconnected PV-battery facility. By comparing it to a non-renewable option, the net present cost and the cost of energy for the on-grid PV-battery technology were greater by $15.6 \%$ and $16.8 \%$, respectively.

Suhane et al. [27] used the ant colony algorithm for an integrated system consisting of PV modules, wind turbines, and batteries. The objective was concentrated to minimise the cost for a selected location in India. Ren et al. [28] employed a novel optimization algorithm for techno-economic optimization for an on-grid PV system integrated with battery and fuel cells. Also, obtaining ideal management and operational strategies were other determinations. Ahmadi et al. [29] applied a new model of techno-economic analysis to find the improved size of an off-grid hybrid PV system integrated with a battery and wind turbine. The thermo-economic analysis of a PV-powered air conditioner has been performed by Aguilar et al. [30]. A comparative study among the PV and power grid as the power supplier for the system revealed that the cost of electricity was 101.81 and $220.46 €$ per year, respectively. Emmanuel et al. [31] put forward an analysis with the economic feasibility of a $10 \mathrm{kWp}$ grid-connected PV system in New Zealand. The performance ratio was from $76 \%$ to $79 \%$. Moreover, at $4 \%, 6 \%$, and $8 \%$ discount rates, the LCOE were $0.121,0.141$, and $0.162 \mathrm{US} \$ / \mathrm{kWh}$, respectively, while the payback period was 6.4 years.

In addition, the economic investigations of PV systems are important in improving the PV technology application as promising renewable energy policies stay to develop internationally. Adaramola [32] conducted the feasibility of the grid-connected PV systems in Nigeria. The research indicated that an $80 \mathrm{kWp}$ plant presented the proper capability to provide around $40 \%$ of the power demands while the LCOE was $0.103 \mathrm{US} \$ / \mathrm{kWh}$. Mondal et al. [33] performed the economic feasibility of a $1 \mathrm{MWp}$ grid-connected PV facility in Bangladesh. Over 15 years of monitoring, they stated that the cost of energy was 0.253-0.282 US\$/kWh, which dropped over time. El-Shimy [34] employed an economic 
feasibility study of a $10 \mathrm{MWp}$ grid-connected PV system for several dissimilar sites. The cost of energy was between 0.1989 and $0.2424 \mathrm{US} \$ / \mathrm{kWh}$, while the payback period varied from 4.9 to 7.1 years. Adaramola [35] analyzed the financial feasibility of a roof-mounted PV unit with a $2.07 \mathrm{~kW}$ capacity. The feed-in tariff was $0.356 \mathrm{US} \$ / \mathrm{kWh}$ during 25 years. Also, the LCOE was 0.246 US\$/kWh. Edalati et al. [36] applied a techno-economic study to a 10 MWp PV system in Iran. The LCOE varied between 0.1992 US\$/kWh in the southern parts of the country to $0.3838 \mathrm{US} \$ / \mathrm{kWh}$ in the northern parts.

To enhance the solar radiation density, amplification systems have been used. In this method, the maximum output power can be increased to several times more than the initial state [37]. The most substantial amplifications happen over the transposition model between $\pm 1 \%$ and $+6 \%$. The amplifications also influence the energy rating considerations since they modify the expected real efficiency of the performance ratio and the modules [5].

This work introduces an innovative method to investigate the PV systems by a direct radiation amplification system based on the technical and economic features. For this approach, at first, various types of solar reflecting systems were examined, which include the photovoltaic system and the biaxial reflector with a solar tracker system. Also, their associated problems and solutions are stated. In this case, by using five interconnected steps, the optimal design of a PV system, located at 35/7525 north and 50/9428 east in the energy research department, has been presented, while the direct radiation amplification system is used. In this proposed system, different phases were studied, which included: (1) Energy rating with associated models. (2) Simulation by MATLAB software. (3) Prototype testing. (4) Testing in a real photovoltaic power plant. (5) Economic analysis. The results of this study showed that by implementing this system in photovoltaic power plants, annual energy production can be increased. Moreover, the parametric studies determined the effects of reflector presence in the system. A review of the existing literature reveals that this type of techno-economic investigation is direct radiation amplification systems that have not been studied and this analysis is a novel method to assess the PV systems.

\section{Design and Simulation}

In the reflector design, several flat reflectors are placed symmetrically with the photovoltaic panels and shine sunlight to another flat reflector, and the second reflector shines a light on the photovoltaic panels. In this system, in addition to solar radiation, photovoltaic panels also receive radiation directed by reflectors on photovoltaic panels, which increases the density of radiation and increases the efficiency of photovoltaic panels.

As shown in Figure 1, there are reflectors on the left while photovoltaic panels are placed on the right, and a second reflector on top. After irradiation, the sunlight is directed to the reflectors on the ground towards the second reflector, and after the reflection, it hits the photovoltaic panels. This allows the solar panels, in addition to direct sunlight, to absorb the radiation directed at them by the reflectors, which ultimately increases energy production.

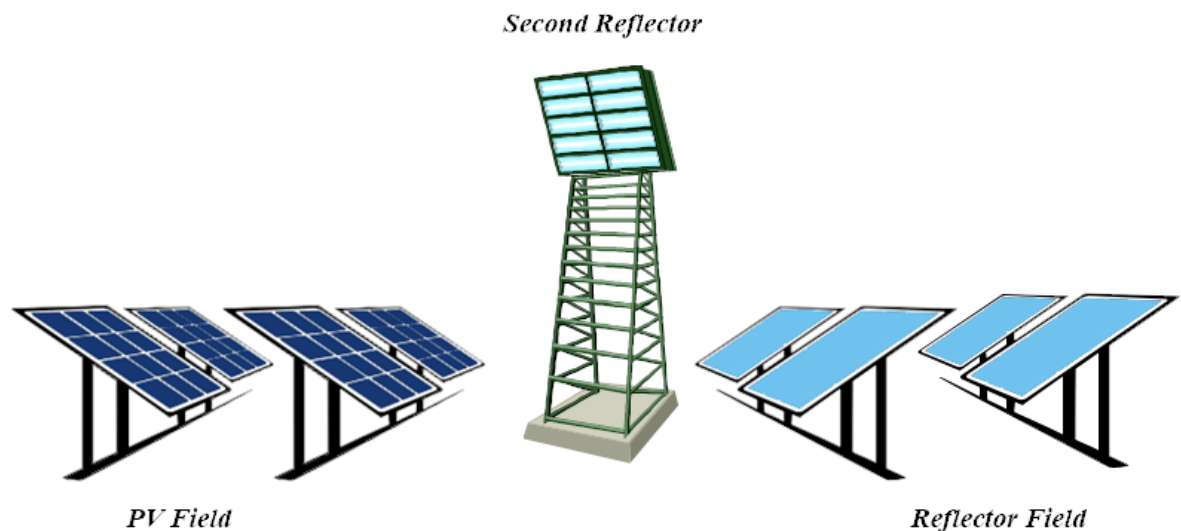

Figure 1. Sunlight to the photovoltaic panel by two reflectors. 
A solar farm is a set of solar energy-based systems that use solar energy to generate electricity. The farm may generate energy using photovoltaic panels or solar reflecting systems. Each of the reflecting systems is called a heliostat. Simply put, heliostats are mirrors that reflect energy reaching the receiver through the sun during the day. Each heliostat consists of a pedestal, a supporting structure, a reflecting surface, and a solar tracking system, which tracks the sun throughout the day and places the heliostat in a position that reflects sunlight toward the receiver.

Solar field efficiency is calculated as follows Equation (1) [38]:

$$
\eta_{\text {field }}=\frac{q_{\text {to ref }}}{q_{\text {from sun }}}
$$

where $q$ from sun is the total heat received from the sun and $q$ to reflector is the overall absorbed heat by the reflector. The total heat received from the sun $\left(q_{\text {from sun }}\right)$ is a function of the intensity of the sun's radiation $I(t)$ and the total radiant area of the solar field is $\left(A_{r e f}\right)$.

$$
q_{\text {from sun }}(t)=I(t) \times A_{\text {ref }}
$$

$I(t)$ indicates the intensity of solar radiation in terms of $\left(W \cdot m^{-2}\right)$ and depends on time and geographical location. The heat flux from the receiver, which is obtained from the reflection of solar radiation by the solar field, is always less than the heat flux received by the heliostats. The phenomena that cause this difference and decrease the efficiency of the solar field are shown as the efficiencies multiplied by the heat received by the sun.

Also, $\eta_{\text {atten }} \cdot \eta_{\text {clean }} \cdot \eta_{\text {ref }} \cdot \eta_{\text {cosine }} \cdot \eta_{B \& S}$ and $q_{\text {from sun }}$ are focusing efficiency, cleaning efficiency, reflection efficiency, cosine efficiency, block, and shadow efficiency, and the total heat received from the sun, respectively.

$$
q_{\text {to ref }}=q_{\text {from sun }} \eta_{\text {atten }} \eta_{\text {clean }} \eta_{\text {ref }} \eta_{\text {cosine }} \eta_{B \& S}
$$

The block and shadow phenomenon express the effect of adjacent heliostats on each other, and this effect is greater when the sun is close to the horizon before sunset and after sunrise. The blocking phenomenon means that the heliostat or part of it can see the sun, but does not see the receiver, as the heliostat is blocked by the heliostat between it and the receiver.

Shadow occurs when the heliostat or part of it is unable to see the sun, that is, the straight line between the heliostat and the sun is intersected by one of the adjacent heliostats. Due to the non-repetitive position of the sun during the day and year, as well as the threedimensional motion of the heliostats, it is very difficult to accurately calculate the distance between the heliostats to minimise the block effect and shadow, and so far, few approximate models have been proposed.

\subsection{Reflection Efficiency $\left(\eta_{\text {ref }}\right)$}

Reflective surfaces of heliostats are never ideal due to fabrication errors, meaning that they do not direct all of the irradiated beams to the receiver and some of it is reflected into the space around the receiver, and wasted. The reflection efficiency $\left(\eta_{\text {ref }}\right)$ shows beams reflected the receiver, which in this project is considered to be 0.9 . This is a number considered by large power plants, and the advancement of technology in the construction of these plates today has increased this efficiency to 0.95 .

\subsection{Surface Cleaning Efficiency $\left(\eta_{\text {clean }}\right)$}

The efficiency point to the cleanliness of the heliostat surfaces (the presence of dust particles) on the heliostat surface is another factor in reducing the efficiency of a heliostat. Heliostat surfaces should be cleaned according to a regular schedule to prevent this loss. In this project, the cleanliness coefficient of 0.98 levels is considered. 


\subsection{Atmospheric Loss Efficiency $\left(\eta_{\text {atten }}\right)$}

Atmospheric loss efficiency is the energy lost by the sun's rays in contact with airborne particles as well as the atmosphere and depends on the clear weather conditions with foggy dust and the distance of the heliostat from the receiver, the following equation is used to calculate the atmospheric losses.

$$
\begin{gathered}
\eta_{\text {atten }}=0.99321-0.0001176 \times S_{0}+1.97 \times 10^{-8} \times S_{0}{ }^{2} \quad\left(S_{0} \leq 1000 \mathrm{~m}\right) \\
\eta_{\text {atten }}=e^{-0.0001106 \times S_{0}} \quad\left(S_{0}>1000 \mathrm{~m}\right)
\end{gathered}
$$

\subsection{Cosine Efficiency ( $\left.\eta_{\text {cosine }}\right)$}

The cosine effect has the most losses in the solar field and plays the most important role in determining the location of the heliostat, which depends on the location of the sun and each heliostat. The cosine is the angle between the normal vector on each heliostat and the angle of the sun's rays on the heliostat, expressing the impressive reflection surface on each heliostat. As can be seen in Figure 2, an angle of zero means that the actual surface and the effective surface are equal, and in this case, the cosine efficiency is equal to one. If this angle becomes greater, the effective surface area and cosine efficiency become shorter, and the cosine efficiency for each heliostat can be obtained from Equation (6) [39].

$$
\eta_{\text {cosine }}=\frac{\sqrt{2}}{2}\left[\sin \alpha \cos \gamma-\cos \left(\theta_{H}-A\right) \cos \alpha \sin \gamma+1\right]^{0.5}
$$

where $\alpha$ is the angle of elevation of the sun, $A$ is the angle of the image of the sun with the direction of the south, $\gamma$ is the angle between the reflected beam from the heliostat with the line perpendicular to the center of the heliostat, and $\theta_{H}$ is the angle of the heliostat from the south to the receiver are shown in Figure 2.

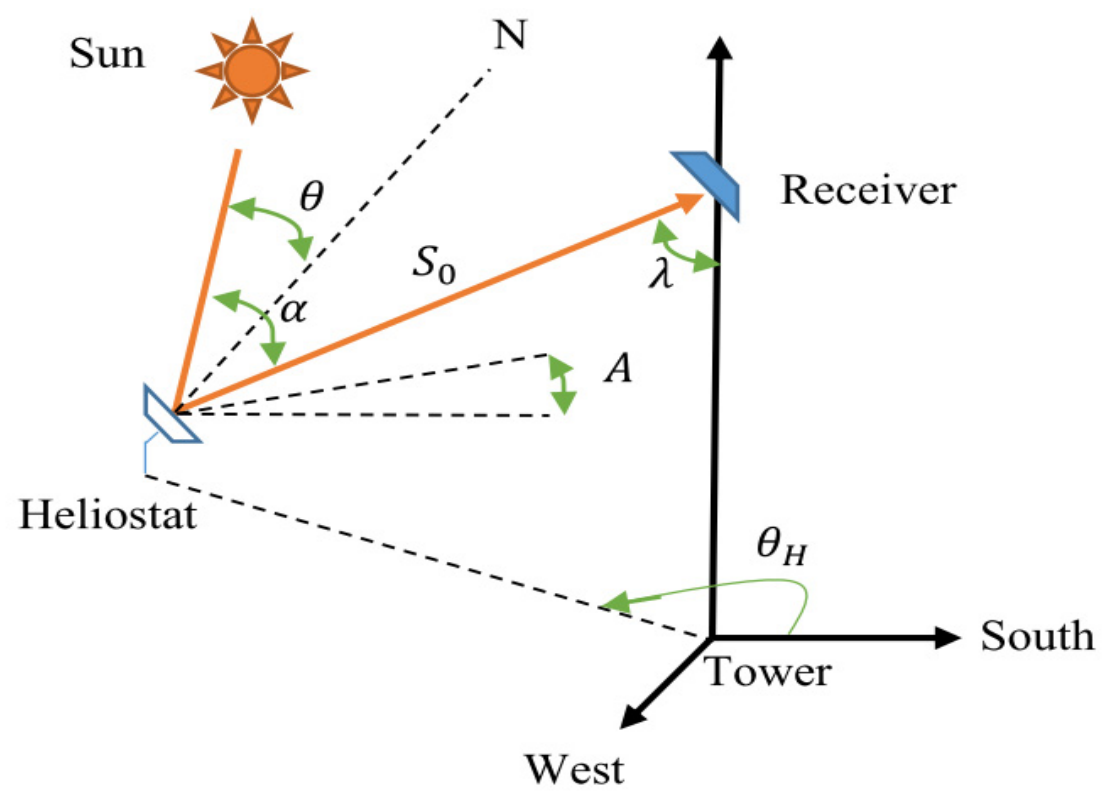

Figure 2. Effective angles in cosine efficiency.

\subsection{Calculating Cosine Efficiency by Using MATLAB Software}

We calculated the cosine effect for the geographical location of the Materials and Energy Research Institute, which is simulated and calculated at 35.75 north and 50.92 east with $\gamma$ angle of 17 degrees for one year. 
For $8760 \mathrm{~h}$ per year for all solar angles in this geographical position, it is calculated using Equation (6) and two graphs are obtained, one graph for $\alpha$ angle of the sun in this position and the other is the cosine coefficient.

These graphs show that on the longest day of the year when the sun is at its greatest angle to the earth's surface, the cosine coefficient is closer to one, and on the shortest day of the year when the sun is at a lower angle, the cosine effect decreases. As shown in Figure 3, this graph is drawn in three dimensions, which are the day, hour, and angle of the sun in the sky. The angle of the sun in the sky is different in each latitude and longitude and this chart is related to the location of the Institute of Materials and Energy. The first day is 1 January and day 365 is 31 December.

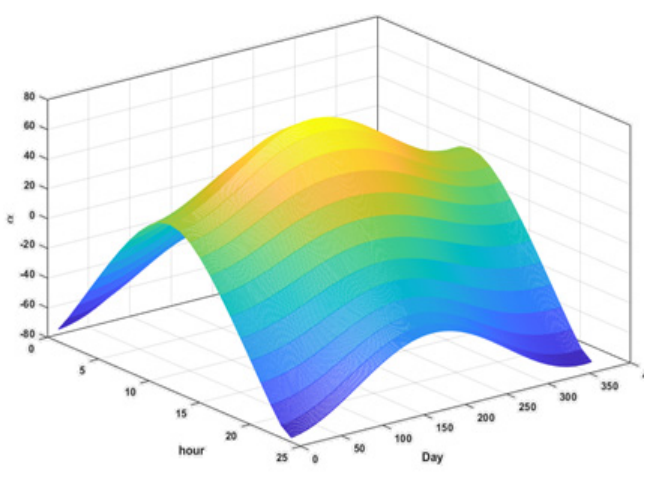

(a)

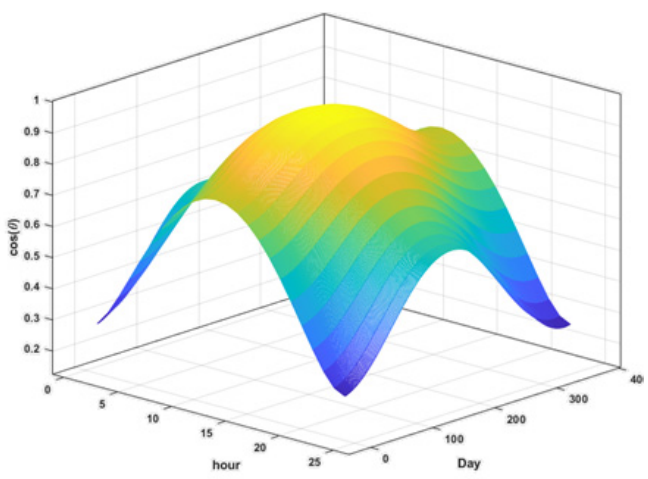

(b)

Figure 3. Cosine efficiency and solar angle diagrams for a year in every hour. (a) Solar angle diagram ( $\alpha$ diagram). (b) Cosine efficiency diagram.

The maximum solar angle always occurs at noon, and the highest noon angle is related to 21 June, which reaches 79 degrees at noon, and the lowest solar noon angle is related to 21 December with 31 degrees. Figure 3 shows the cosine efficiency and $\alpha$ diagrams and it is drawn by using MATLAB software every one hour for a year. Figure $3 a$ is drawn by using Equation (7).

$$
\begin{gathered}
\theta=\cos ^{-1}(\cos \varphi \cos \delta \cos \omega+\sin \varphi \sin \delta) \\
\delta=23.45 \sin \left(360 \frac{284+n}{365}\right)
\end{gathered}
$$

where, $\theta, \delta, \varphi$ and $\omega$ are the day of the year, deviation, latitude, solar noon angle respectively [40].

In Figure $3 b$, the diagram is related to cosine efficiency, which is calculated and plotted once every hour for one year. This diagram is solving Equation (6) for a year and once every hour, which is drawn using MATLAB software.

This diagram is drawn in three dimensions based on the day of the year, hours, and cosine efficiency. Day 1 corresponds to the 1 January and day 365 corresponds to 31 December. The cosine efficiency varies throughout the year and the day. The cosine efficiency will reach its maximum during the day at noon. By paying more attention to Figure $3 b$, it is found that the solar angle diagram is similar to the cosine efficiency diagram. The cosine efficiency depends on the solar angle and can also be seen in Equation (6). It should be noted that the cosine efficiency diagram is different for each geographical position because the solar angle is also different for each geographical position.

\subsection{Economic Analysis}

The construction of a power plant can be undertaken in two ways, one with fixed structures and without a solar tracker, and in the second case using a single-axis tracker. Considering that the construction price of a power plant with a single-axis tracker with dimensions of $5 \mathrm{MW}$ is $\$ 1.46$ (dollars) per watt $(\mathrm{W})$ and the construction price of its structure 
is 13 cents per watt, and assuming that a $300 \mathrm{~W}$ panel has dimensions of 2 meters in length and 1 meter in width, it can be concluded that the cost of building a single-axis solar tracker structure is $\$ 19.50$ per square meter. The price of reflectors was also investigated, which is priced at 5 cents per square meter for large-scale production. Therefore, the cost of building a reflective system will be $\$ 19.55$ per square meter.

Considering the cost of building a photovoltaic power plant per watt in 2019 is around $\$ 1.2$, it costs $\$ 0.94$ to build a photovoltaic power plant at its minimum capacity at a steadystate, which will be $\$ 28,200$ for a $30 \mathrm{~kW}$ power plant [41].

For example, a $30 \mathrm{~kW}$ photovoltaic power plant in Tehran will produce $51,000 \mathrm{kWh}$ of energy per year. The relation $A=P \frac{r(1+r)^{n}}{(1+r)^{n}}$ converts the investment cost to the annual converted cost. In this regard, $\mathrm{A}$ is the annual conversion cost, $\mathrm{P}$ is the current investment cost, $\mathrm{r}$ is the discount rate and $\mathrm{n}$ is the number of periods. Here, the discount rate is $20 \%$ and the number of courses is 20 . One of the most important factors for building a power plant is the amount of investment per kilowatt-hour $(\mathrm{kW} / \mathrm{h})$ of energy produced. Currently, the investment for a photovoltaic power plant is $\$ 1060$ per kilowatt. For example, for a $30 \mathrm{~kW}$ power plant covered in this study, the capital required to build it would be $\$ 28,200$. Because the amount of energy production is not the same everywhere, the length of the cost of production per kilowatt-hour is not the same everywhere, and the main reason is the amount of radiation during a year.

The construction cost per kilowatt of a photovoltaic power plant, plus the maintenance cost per kilowatt, is $\$ 1100$, and if we convert this number into an annual cost and finally divide it by the amount of energy produced per year, in which case the cost is 13 cents per kilowatt-hour. For power plants that use a direct radiation boost system, the construction cost will be $\$ 1314$ per kilowatt with maintenance costs. If we convert this number into an annual cost and finally divide it by the amount of energy produced per year, in which case it will cost 9 cents per kilowatt-hour. By comparing the cost per kilowatt-hour, production is reduced by $31 \%$.

\section{Results and Discussion}

\subsection{Methodology of Pilot Tests}

As shown in Figure 4, this system consists of two reflectors and a photovoltaic panel. Reflector 1 moves with the sun in the sky and constantly reflects sunlight to reflector 2 . Reflector 2 is fixed and its task is to reflect the radiation received from reflector 1 to the photovoltaic panel. In fact, in addition to sunlight, the panel also receives the beams that the reflector emits.

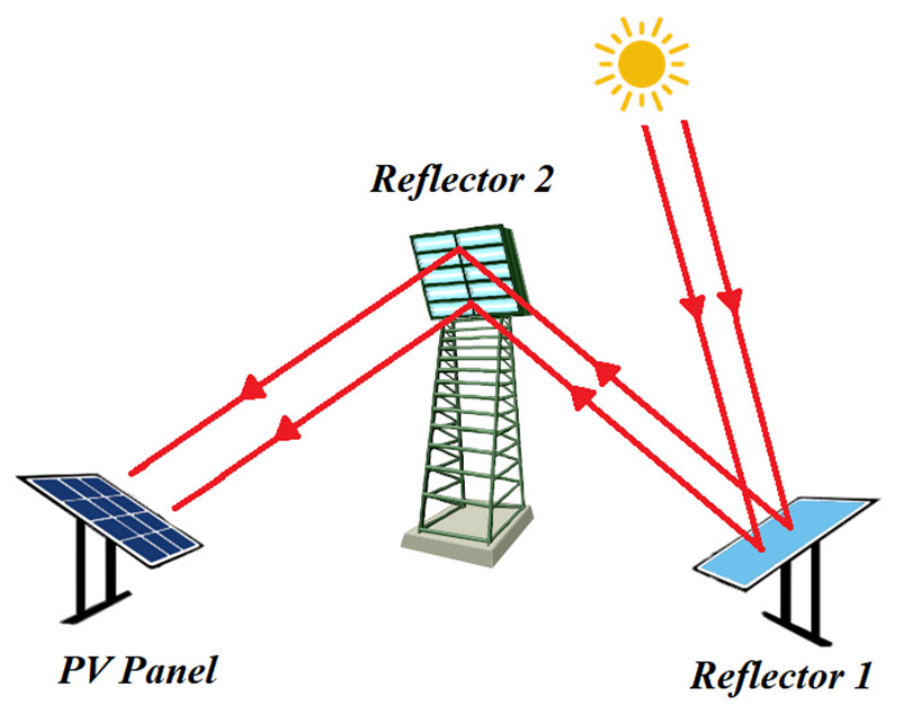

Figure 4. Schematic view. 
The dimensions of the reflectors used in this test are $1 \times 1 \mathrm{~m}^{2}$ with ordinary mirror type. The photovoltaic panel used is a $60 \mathrm{~W}$ panel of the Yingli Solar Company; model YL060P, which measures $66 \times 67 \mathrm{~cm}^{2}$. The technical specifications for panels used in tests are shown in Table 1.

Table 1. Technical specifications of the photovoltaic panel used in the test.

\begin{tabular}{cc}
\hline Yingli & Name of Manufacturer \\
\hline $60 \mathrm{~W}$ & Power \\
$13.5 \%$ & Panel efficiency \\
22.1 volts & Open circuit voltage \\
3.66 amps & Short circuit current \\
$-0.45 \%$ per & ${ }^{\circ} \mathrm{C}$ \\
of $-45^{\circ} \mathrm{C}$ to $85^{\circ} \mathrm{C}$ & Temperature coefficient in terms of power \\
\hline
\end{tabular}

In Table 1 , the operating efficiency of the photovoltaic panel is between $-40^{\circ} \mathrm{C}$ and $85^{\circ} \mathrm{C}$, it can produce energy in this temperature range. Temperature efficiency coefficient in terms of power is $0.45 \%$ per ${ }^{\circ} \mathrm{C}$, given that the standard of measurement in solar panels for radiation of $1000 \mathrm{~W} / \mathrm{m}^{2}$ is an ambient temperature of $25^{\circ} \mathrm{C}$, the coefficient of temperature efficiency in terms of power means that for each ${ }^{\circ} \mathrm{C}$ more than $25{ }^{\circ} \mathrm{C}, 45 \%$ of the power of the photovoltaic panel is reduced which is one of the most important specifications for competition among manufacturers of photovoltaic panels to reduce this number and is one of the important features in the price of photovoltaic panels. The efficiency of a photovoltaic panel means that it will convert $13.5 \%$ of the received energy into electrical energy for $1000 \mathrm{~W} / \mathrm{m}^{2}$ of radiation at $25^{\circ} \mathrm{C}$.

Figure 5 shows the overview of the project include reflector 1 (Figure $5 \mathrm{a}$ ), reflector 2 (Figure $5 b$ ), and total view of the project (Figure $5 c$ ). As can be seen in Figure $5 a, b$, reflector 1 and 2 measure $1 \times 1 \mathrm{~m}^{2}$. The reflection coefficient in these reflectors is considered to be 0.9 . That means, they will reflect $90 \%$ of the received radiation. Figure $5 \mathrm{c}$ shows the view of the project. As can be seen, two reflectors reflect solar irradiation to the photovoltaic panel. Reflector 1 is equipped with two gearboxes for moving on two axes which is to adjust the reflection of sunlight and direct it to the second reflector. As a result, reflector 2 directs the radiation received from reflector 1 to the photovoltaic panel.

\subsection{Test Days}

In this experiment, analyses such as temperature analysis, wind speed, humidity, photovoltaic power analysis with and without reflectors, potential difference, and current intensity at different hours of the day were performed. This experiment was performed to verify the results on two different days, 28 July 2020, in the middle of summer, as test 1 , and 20 December 2020, the last day of autumn, as test 2. 


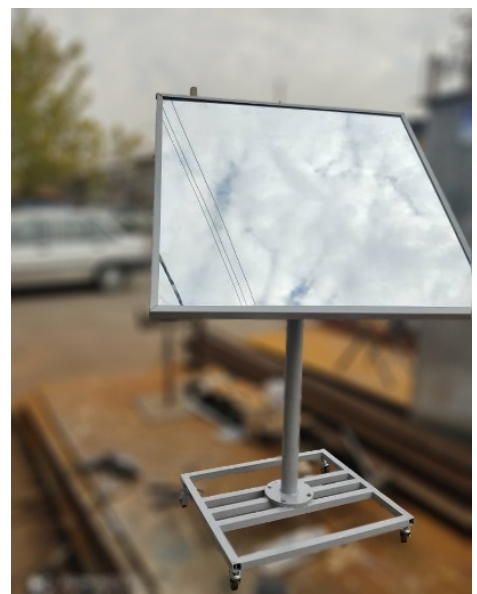

(a)

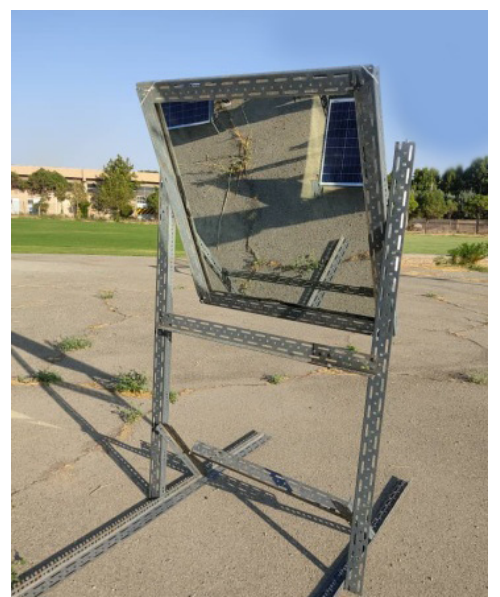

(b)

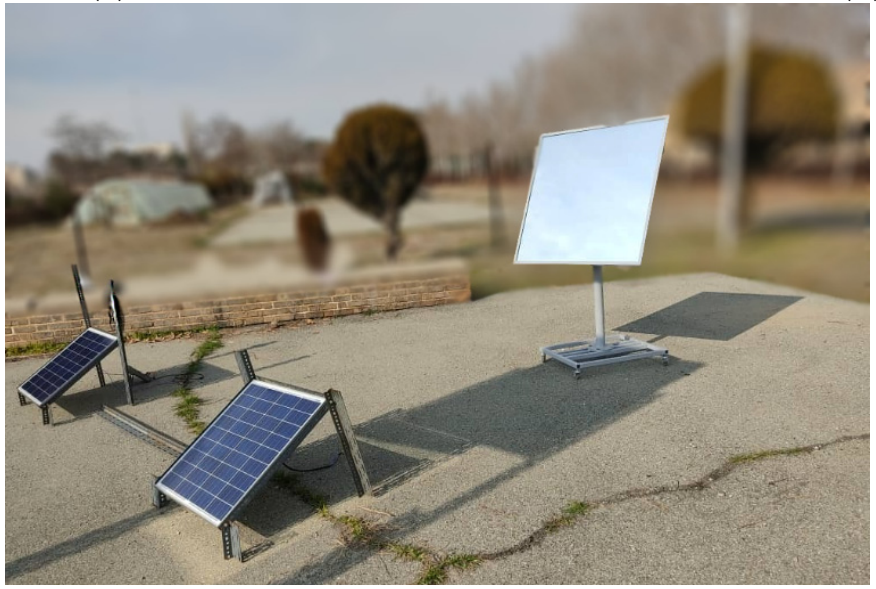

(c)

Figure 5. Overview of Reflectors 1, 2 and the location of the project. (a) Reflector 1. (b) Reflector 2. (c) View of the project.

\subsubsection{Measurement and Analysis of Temperature Variables}

Three temperatures are measured during the test to compare them to obtain better results. These temperatures include:

(1) $T_{1}$ : panel surface temperature without the use of reflectors

(2) $T_{\text {ambient }}$ : ambient temperatures

(3) $T_{2}$ : panel surface temperatures with reflector mode.

Three temperatures are measured every $15 \mathrm{~min}$. $T_{\text {ambient }}$ is always lower than $T_{1}$ and $T_{1}$ is lower than $T_{2}\left(T_{2}>T_{1}>T_{\text {ambient }}\right)$, but this difference is not constant at the time of testing and varies according to the diagrams of Figure 6 . In this diagram, the horizontal axis shows the time and the vertical axis shows the temperature in ${ }^{\circ} \mathrm{C}$. The surface temperature of a photovoltaic panel with a reflector is always higher than the surface temperature of a photovoltaic panel without a reflector, and this is because the radiation is always higher when using a reflector. The temperature difference between the beginning and the end of the day is smaller and this is due to the reduction of radiation at these times of the day. The more radiation, the greater the difference. The ambient temperature is always lower than the surface temperature of the photovoltaic panel. 


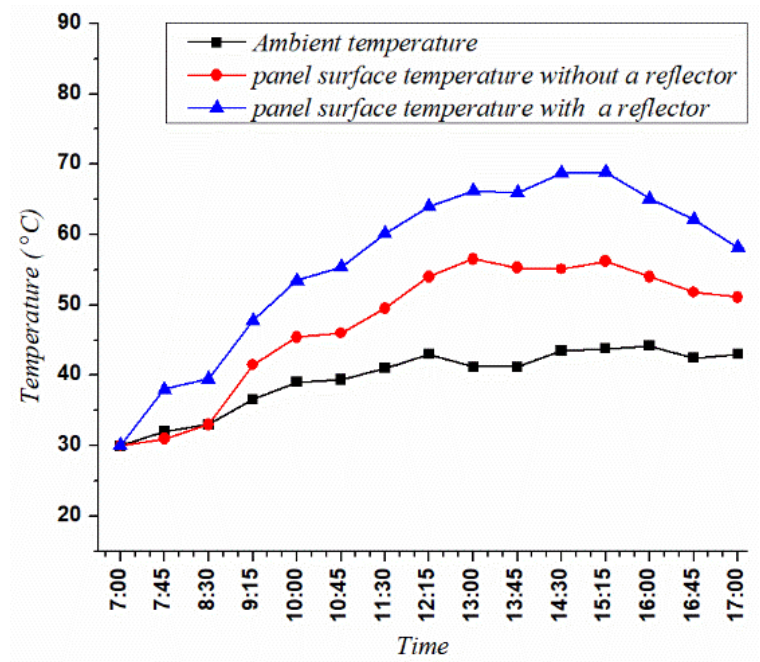

Test 1 (July 28, 2020)

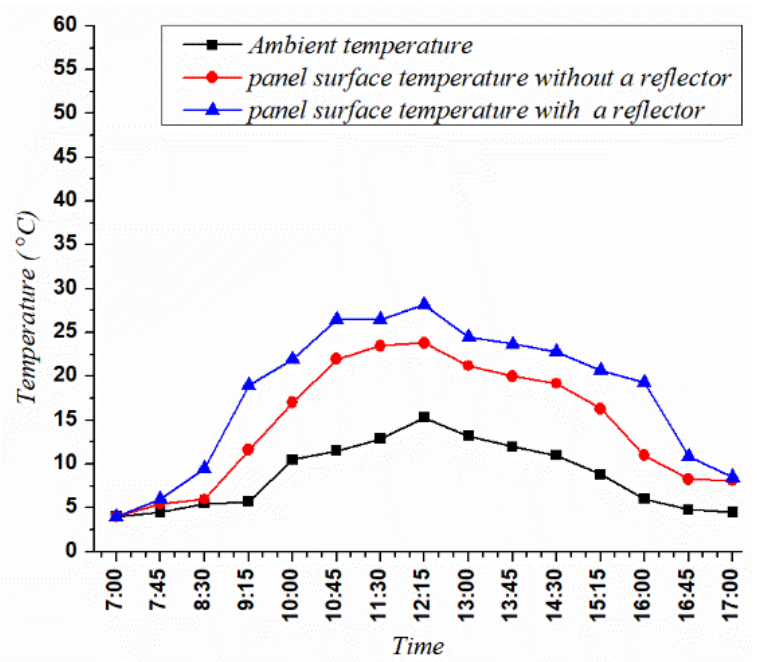

Test 2 (December 20, 2020)

Figure 6. Ambient temperature diagram and panel surface temperature with and without a reflector.

According to Figure 6, the temperature difference between the surface of the solar panel with reflector and without reflector at the most times not exceed $10^{\circ} \mathrm{C}$. Although this $10{ }^{\circ} \mathrm{C}$ increase in the surface of the solar panel reduces production efficiency by $4.5 \%$, increasing the density of solar irradiation compensates for this plunge of efficiency.

\subsubsection{Measurement and Analysis of Wind Velocity and Humidity Variables}

Wind velocity was measured using an anemometer which is shown in Figure 7a. In this diagram, the horizontal axis shows the time and the vertical axis demonstrates the velocity $(\mathrm{m} / \mathrm{s})$. As can be seen, the wind velocity is variable and it should be noted that the wind velocity is measured perpendicular to the panel. The wind velocity changes a lot and these changes affect the panel surface temperature so that as the wind speed increases, the panel surface temperature decreases and the wind velocity due to effects the temperature of the photovoltaic panel and the temperature of the photovoltaic panel affects the efficiency of the photovoltaic panel. Therefore, it can be concluded that increasing wind velocity increases the efficiency of the photovoltaic panel.

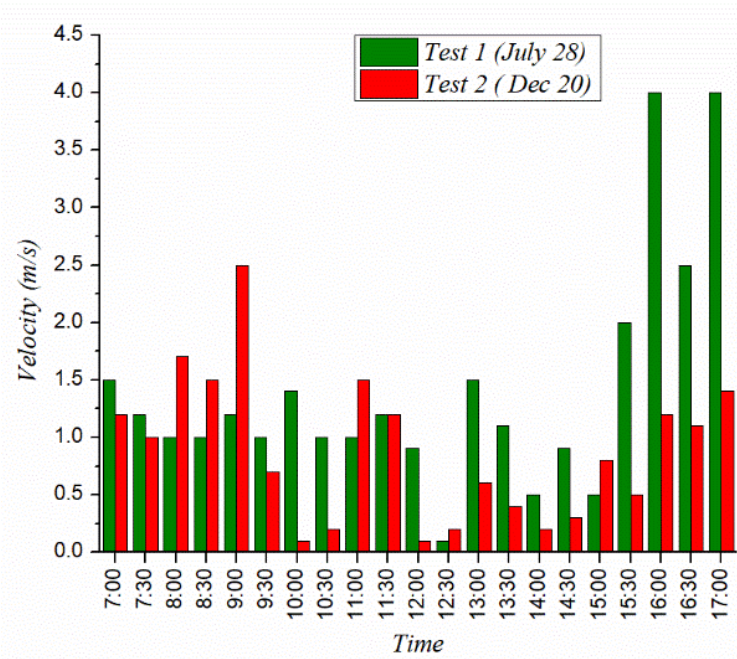

(a)

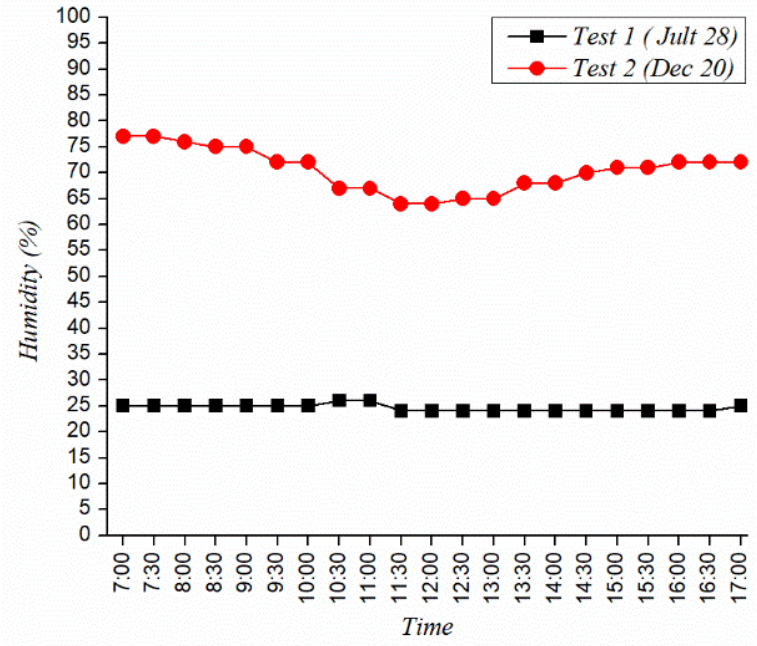

(b)

Figure 7. Wind velocity diagram and humidity diagram. (a) Wind velocity diagram. (b) Humidity diagram. 
Humidity is almost constant throughout the day, as measured every $15 \mathrm{~min}$. This is shown in Figure $7 \mathrm{~b}$. In this figure, the horizontal axis shows the time and the vertical axis shows the percentage of humidity. As can be seen in Figure $7 \mathrm{~b}$, the humidity increases slightly at the beginning and end of the day and remains almost unchanged throughout the day. Humidity reduces the amount of solar radiation. Humidity also reduces direct radiation and increases indirect radiation due to the collision of light rays with air molecules.

\subsubsection{Measurement and Analysis of Radiation Variables}

The amount of radiation is measured by a radiometer every $15 \mathrm{~min}$. As can be seen in Figure 8, the radiation starts to increase in the morning and reaches its maximum at sunny noon. In Figure 8, two radiations are measured, the radiation on the photovoltaic panel with and without reflector, which is compared in the following diagram. In Figure 8, the panel always has more radiation with the reflector, but the important point is that their difference is not constant because radiation is dependent on the cosine efficiency and cosine efficiency is also dependent on the solar angle so that the cosine efficiency is not constant. Therefore, the difference between the radiations is not constant, which will reach its maximum at noon.

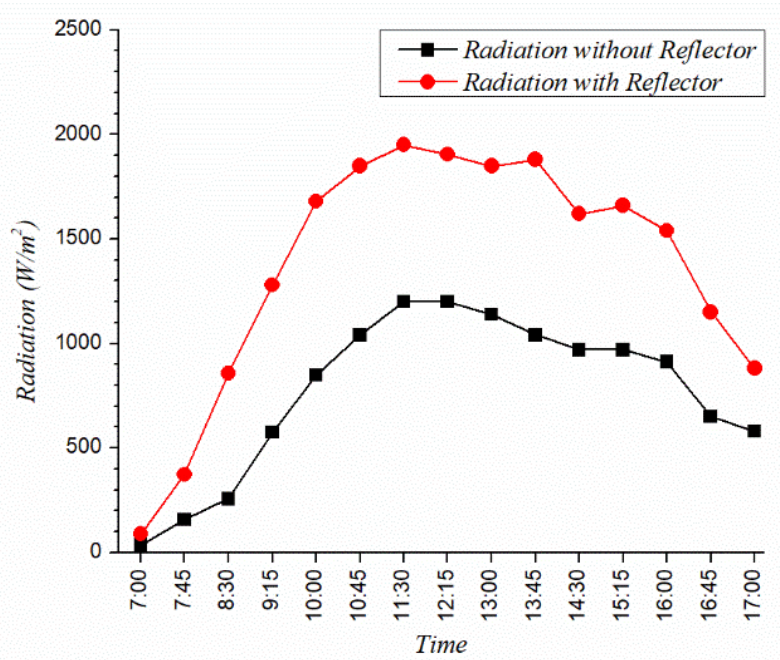

Test 1 (July 28, 2020)

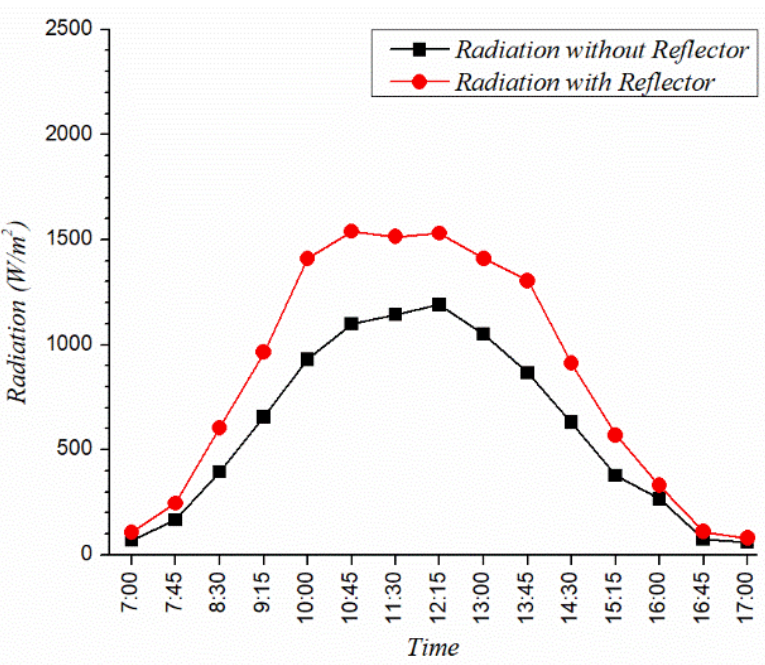

Test 2 (December 20, 2020)

Figure 8. Radiation diagram with and without the reflector.

\subsubsection{Measurement and Analysis of Potential Difference Variables}

The potential difference (voltage) is measured simultaneously for two panels, the panel with and without the reflector, but gradually this distance decreased and even in a few moments the potential difference for the panel without reflector increased from the panel with the reflector, but again at the end of the test the potential difference with the reflector increased. The potential difference is one of the variables in which the changes are small. As can be seen in Figure 9, the potential difference in both modes, with and without the reflector, decreases at noon and increases at the end of the day due to the increase in panel surface temperature at noon and decrease in temperature at the beginning and end of the day. 


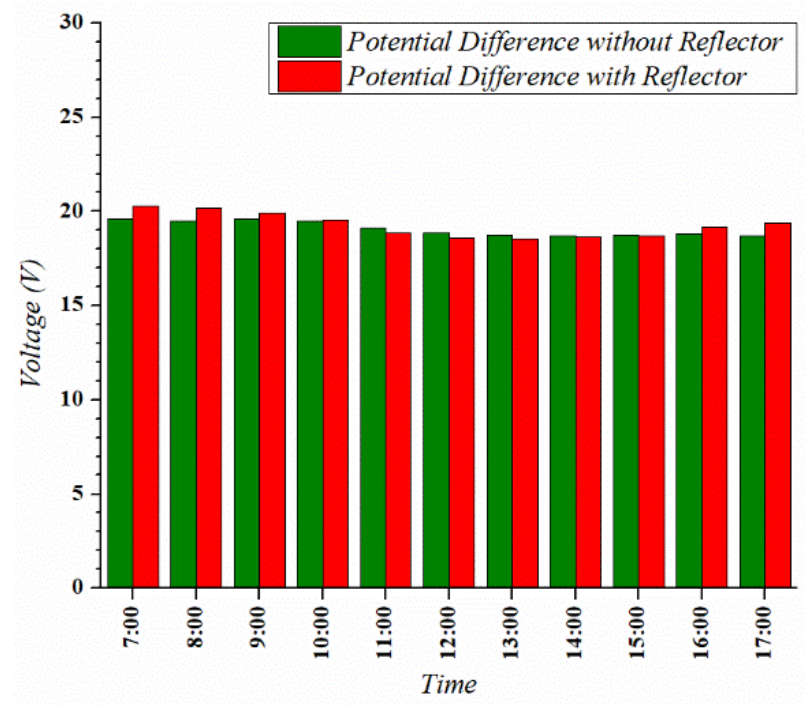

Test 1 (July 28, 2020)

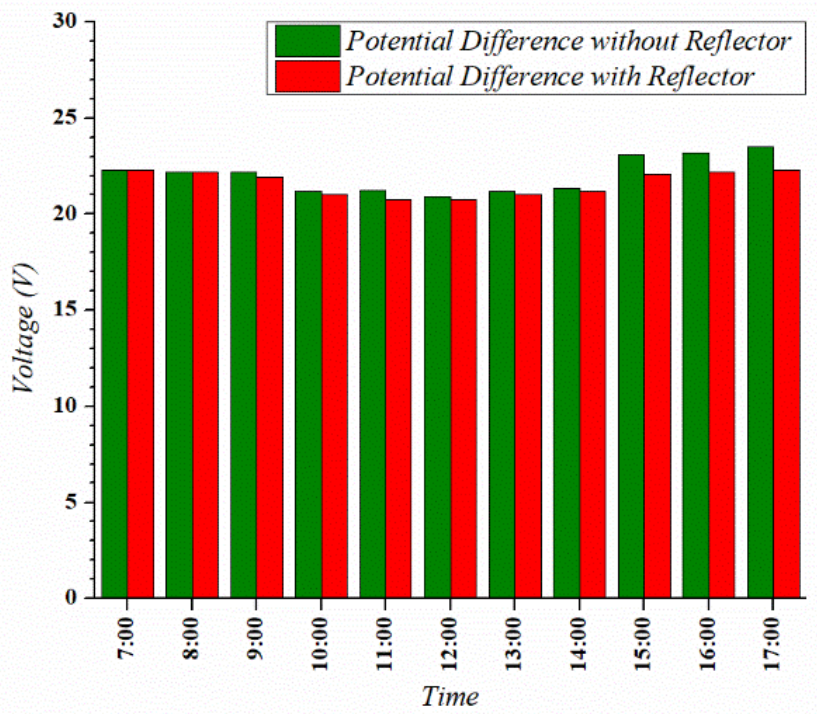

Test 2 (December 20, 2020)

Figure 9. Comparison of potential difference with reflector and without the reflector.

\subsubsection{Measuring and Analyzing Current Variables}

The current (amperage) is measured for the panel with and without a reflector, simultaneously. As can be seen in Figure 10, the current in the panel with the reflector is always higher, but their difference was not constant and depends on the radiation. Regarding Figure 10, the current diagram is very similar to the radiation diagram (Figure 8), which shows that the current is directly related to the radiation, and the power is equal to the product of the current in the potential difference, and so according to the constant potential difference, it can be concluded that with increasing radiation, the power increases and thus increases the current. The chart reaches its maximum at noon, and at the beginning and end of the day when the radiation is low, the electric current also shows a low number.

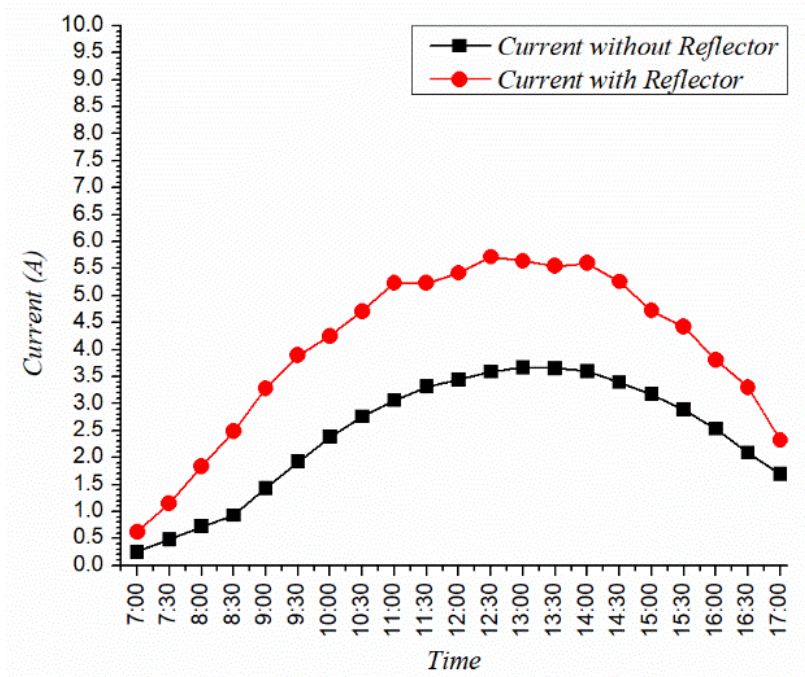

Test 1 (July 28, 2020)

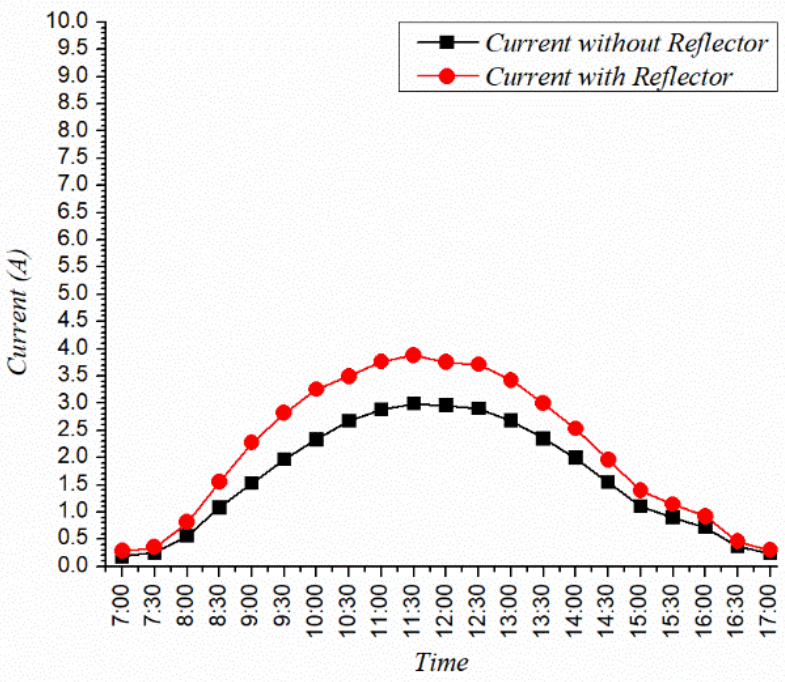

Test 2 (December 20, 2020)

Figure 10. Comparison of currents of panels with reflector and without the reflector. 


\subsubsection{Measurement and Analysis of Power Variables}

The output power of the panel with a reflector and the panel without a reflector is shown in Figure 11. In this diagram, the power of the panel with the reflector is always higher than the panel without the reflector. Increased radiation is had a significant effect on increasing power. The output power for test 1 (which is the result of multiplying the current at any moment in its potential difference) is 80.54 for the panel with a reflector and $48.92 \mathrm{~W}$ for the panel without the reflector. The maximum power is in the panel with a reflector at 12:30 with $106.16 \mathrm{~W}$, while the output of the panel without reflector at 13:00 is $68.81 \mathrm{~W}$. By comparing the average outputs, it is concluded that the effect of these reflectors shows a $64.63 \%$ increase in power. Another factor that affects power is cosine efficiency.

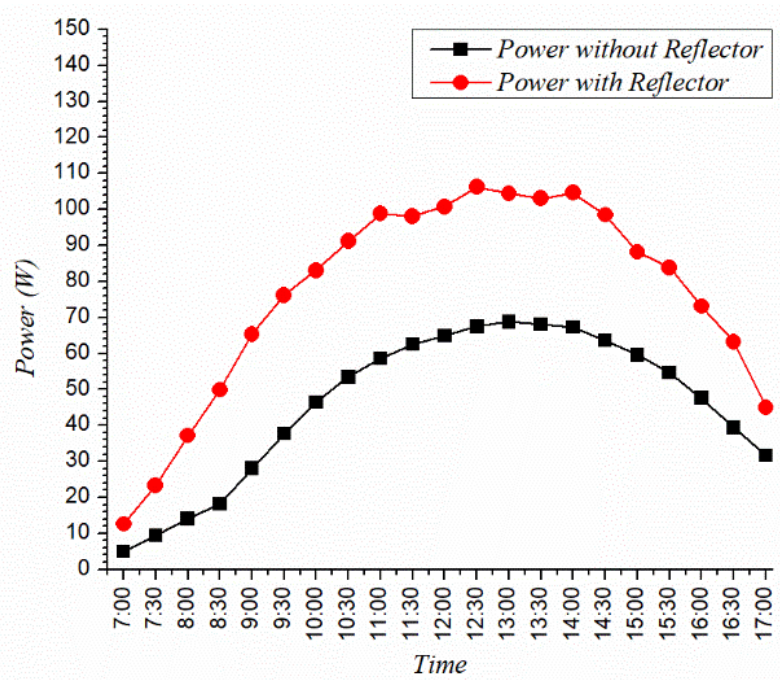

Test 1 (28 July 2020)

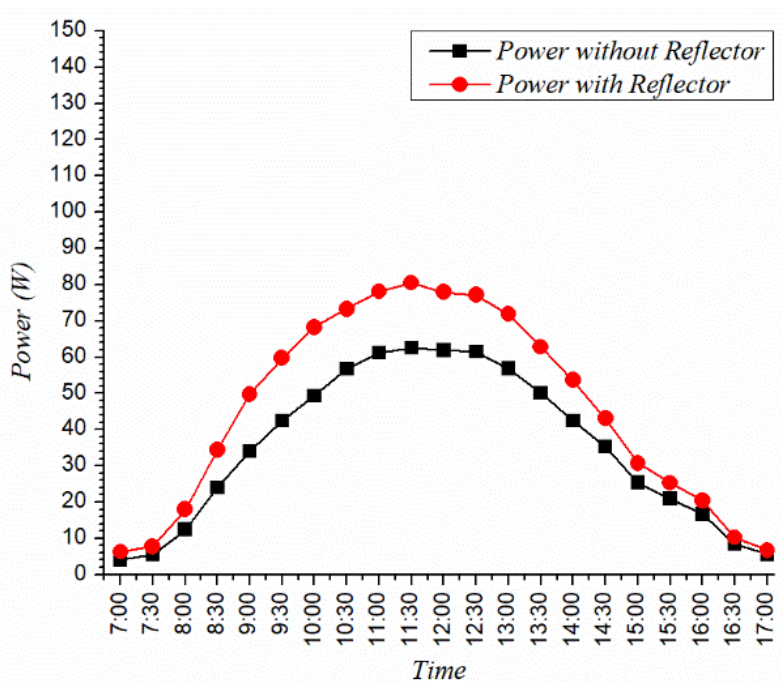

Test 2 (20 December 2020)

Figure 11. Comparison of powers of the panel with reflector and without the reflector.

The output power of the panel with reflector is 46.1 watts for test 2, while the panel without reflector was $35.5 \mathrm{~W}$ on average. The maximum power in the panel with reflector is $82.9 \mathrm{~W}$ at $11: 45 \mathrm{am}$, while the panel without a reflector has an output of $63.75 \mathrm{~W}$ at 11:45 The effect of reflectors on the output power of the photovoltaic panel can be seen in Figure 11.

\subsection{Comparison of Test Results}

In test 1 , when the power produced by a photovoltaic panel in two modes using a reflector and without using a reflector is compared, it is seen that the average power in the mode using a reflector is $80.54 \mathrm{~W} / \mathrm{h}$. Moreover, in the case without the use of reflectors, the average is $48.92 \mathrm{~W} / \mathrm{h}$.

By comparing these two values, it can be seen the effect of the reflector on the increase of power, which shows an average of $64.63 \%$ increase. This number is calculated by Equation (9) [33].

$$
P=I \times \eta_{\cos ^{2}}^{2} \times \eta_{r e f}^{2} \times A \times \eta_{\text {panel }}
$$

In this regard, $I$ is the sun's radiation, $\eta_{\cos }$ is a cosine efficiency, because it is reflected twice, it can reach $2, \eta_{\text {ref }}$ is the efficiency of the reflector, and it is reached 2 because it is reflected twice, $A$ is the cross-section of the panel is photovoltaic, and $\eta_{\text {panel }}$ is the efficiency of the panel is photovoltaic. By using Equation (9), the productive power can be calculated. By comparing the experimental power with the computational power, the difference between these numbers is $1-2 \%$.

In test 2 , the average power output in the model without using a reflector is $35.5 \mathrm{~W} / \mathrm{h}$ and in the mode using a reflector is $46.1 \mathrm{~W} / \mathrm{h}$. In this test, using Equation (9), when the 
calculated powers with the measured values are compared, the difference between these numbers shows 1 to $2 \%$ error. The main reason for this error is the lack of calibration of measuring equipment.

\subsection{Testing at the $30 \mathrm{~kW}$ Photovoltaic Power Plant of the Materials and Energy Research Institute}

The $30 \mathrm{~kW}$ photovoltaic power plant is located on land with dimensions of $33 \times 21 \mathrm{~m}$. The power plant consists of 120 solar panels with a capacity of $250 \mathrm{~W}$ arranged in six rows of 18 and a row of 12 , at an angle to the south and an angle of $45^{\circ}$ to the horizon. The back-to-back distance between the panels is 5 meters, which is to prevent shadows on each other. Also, 2 inverters are used to convert DC to AC power with $15 \mathrm{~kW}$ capacity.

Technical Specifications of Photovoltaic Panel Used in Power Plants

Table 2 shows the technical specifications of the photovoltaic panel used in the $30 \mathrm{~kW}$ power plant of the Materials and Energy Research Institute. Power efficiency decreases in terms of power based on the standard temperature of $25^{\circ} \mathrm{C}$ for each degree Celsius increase.

Table 2. Technical specifications of power plant photovoltaic panel.

\begin{tabular}{cc}
\hline $250 \mathrm{~W}$ & Power \\
\hline $15 \%$ & Radiation efficiency \\
\hline$-0.45 \%$ per ${ }^{\circ} \mathrm{C}$ & Power efficiency in terms of power \\
\hline$-45^{\circ} \mathrm{C}$ to $85^{\circ} \mathrm{C}$ & Operating temperature range \\
\hline
\end{tabular}

Table 3 shows the technical specifications of the inverter used in the studied photovoltaic power plant.

Table 3. Technical specifications of the inverter used in the power plant.

\begin{tabular}{cc}
\hline $\mathbf{1 5 , 0 0 0 ~ V}$ & DC to AC Power Conversion Power \\
\hline 240 to $800 \mathrm{~V}$ & Operating voltage range \\
\hline 33 amps & Maximum input current \\
\hline $98 \%$ & Work efficiency \\
\hline
\end{tabular}

To test the reflector system at the photovoltaic plant, the system was first tested in the same way as the tests performed using two reflectors, as shown in Figure 12a. By using this system, the amount of radiation on a $250 \mathrm{~W}$ photovoltaic panel was increased, which increases the power for a photovoltaic panel. To calculate the amount of excess amount of produced energy in this power plant using Equation (9), the amount of power increase can be calculated using this system. Considering that the test was performed at 11:00 a.m. on 27 December, the cosine efficiency value for the geographical location of the research institute was 0.67 .

The reflectance efficiency was 0.85 , the photovoltaic panel efficiency was 0.15 , and the photovoltaic cross-section was $1.66 \mathrm{~m}^{2}$ and the amount of radiation was $800 \mathrm{w} / \mathrm{m}^{2}$. Using Equation (9), the excess amount of energy produced by the reflector can be obtained. the amount of excess energy produced is as follows:

$$
P=800 \times(0.67)^{2} \times(0.85)^{2} \times 1.66 \times 0.15=64.6 \mathrm{w}
$$




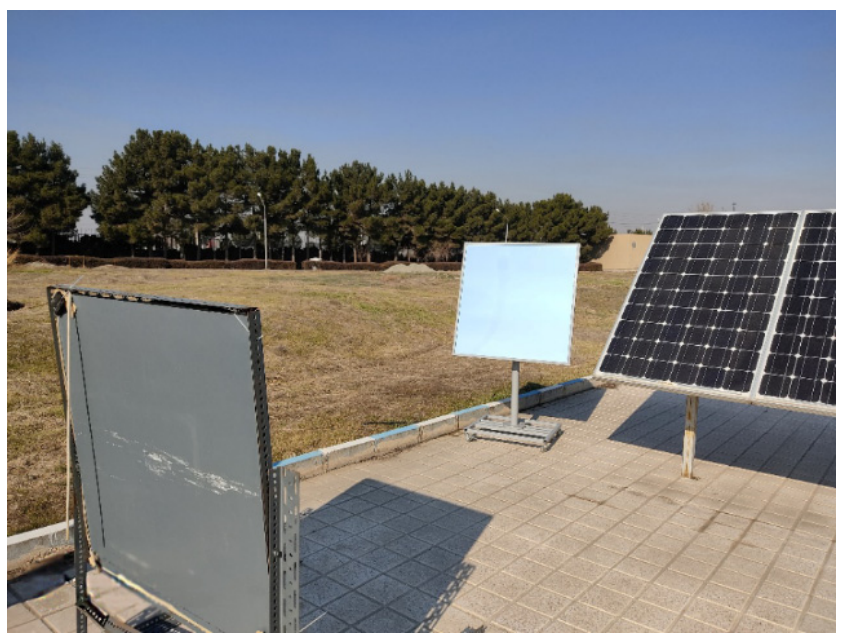

(a)

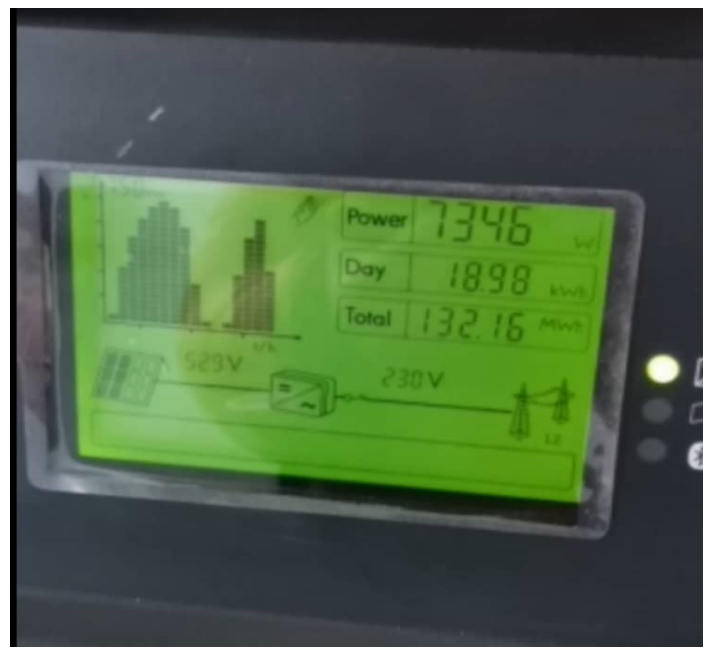

(b)

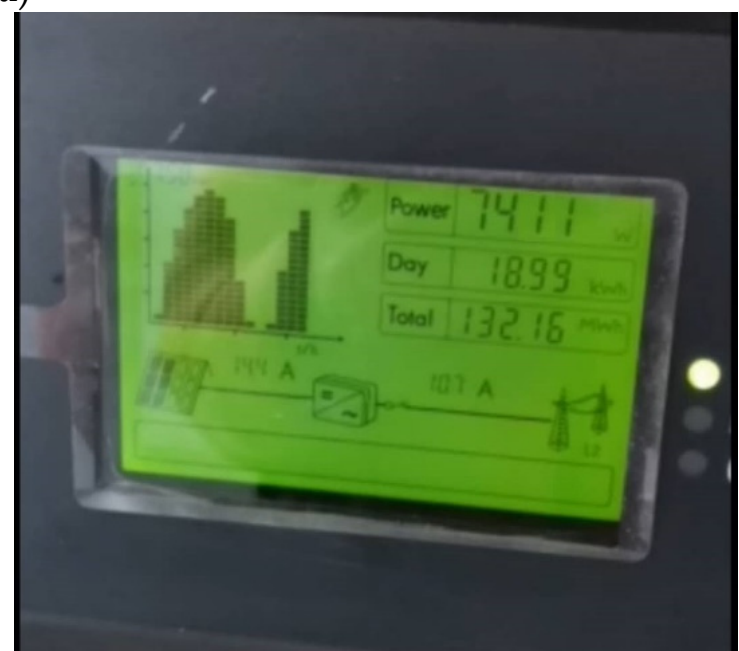

(c)

Figure 12. Test results in the research power plant. (a) Testing at the research plant. (b)Test results without using reflectors. (c)Test results with using reflectors.

In this case, $64.6 \mathrm{~W}$ of power increase was calculated. The system was tested on a $30 \mathrm{~kW}$ power plant to observe the results of this system on a real power plant.

In this test, using two reflectors, a fixed reflector, and a moving reflector, it can reflect direct radiation on one of the photovoltaic panels. At the same time, the inverter output was examined, which shows that the increase in power was due to increased radiation. This amount of excess energy produced by the reflector was directly related to the increase in radiation.

As demonstrated by Figure 12, during the test, the amount of radiation was $800 \mathrm{w} / \mathrm{m}^{2}$ and the amount of radiation with the reflector reached $1056 \mathrm{w} / \mathrm{m}^{2}$. The amount of power change also increased by $65 \mathrm{~W}$. This amount of increase was for a $250 \mathrm{~W}$ panel and the test was only done on one panel. This value was consistent with the data obtained in previous tests and these results confirmed the accuracy of the results of previous tests. According to Figure $12 b, c$, the amount of power output in one of the inverters of the research power plant shows the radiation in two modes using the radiation boosting system and without using the radiation boosting system. In the case of using the radiation amplification system, its output reaches to $7411 \mathrm{~W}$ and in the case without using this system, it shows $7346 \mathrm{~W}$, which indicates an increase of $65 \mathrm{~W}$ of power using the radiation amplifier system. 


\title{
4. Conclusions
}

In this work, an attempt has been made to increase the amount of radiation in photovoltaic power plants by using this system until the average radiation. This increase in radiation density improves the energy production by photovoltaic panels. The amount of increase in solar radiation using this system depends on various factors such as reflection coefficient, geographical location, temperature, the efficiency of photovoltaic panels, the amount of radiation, and weather conditions. Most of the aforementioned factors provide the conditions for increasing radiation on the photovoltaic panel. In this procedure higher values of the temperature coefficient can be obtained by increasing the temperature of the photovoltaic panel, which improves the efficiency of the system.

- The results of this research show that by using reflectors in solar panels in test 1 (28 July 2020) and test 2 (20 December 2020), energy production increases by $64.46 \%$ and $29.84 \%$, respectively.

- According to the cosine and solar diagrams; which were calculated by Matlab software; the maximum solar angle and cosine efficiency always occur at noon, and the highest noon angle is related to 21 June, which reaches 79 degrees at noon, and the lowest noon angle is related to 21 December 21 with 31 degrees.

- The use of reflectors on a solar panel in a research plant showed a $65 \mathrm{~W}$ increase in output compared to the non-reflector mode.

- Although the cost of establishing and maintaining a photovoltaic power plant with a direct radiation amplification system increases from $\$ 1100$ to $\$ 1314$ per kilowatt, the cost of generating power decreases by $31 \%$ from 13 cents to 9 cents per kilowatt.

\begin{abstract}
Author Contributions: Conceptualization, S.H. and M.H.G.; Data curation, H.K.S., S.H., M.H.G. and F.E.; Formal analysis, H.K.S., S.H. and M.H.G.; Funding acquisition, H.K.S., S.H. and D.A.G.; Investigation, H.K.S., M.H.G. and F.E.; Methodology, H.K.S., S.H., M.H.G. and F.E.; Project administration, H.K.S., S.H. and D.A.G.; Resources, H.K.S., S.H. and F.E.; Software, H.K.S.; Supervision, S.H. and D.A.G.; Writing-original draft, H.G. All authors have read and agreed to the published version of the manuscript.
\end{abstract}

Funding: This research received no external funding.

Conflicts of Interest: The authors declare no conflict of interest.

\section{References}

1. Sohani, A.; Sayyaadi, H.; Mohammadhosseini, N. Comparative study of the conventional types of heat and mass exchangers to achieve the best design of dew point evaporative coolers at diverse climatic conditions. Energy Convers. Manag. 2018, 158, 327-345. [CrossRef]

2. Esmaeilion, F.; Ahmadi, A.; Hoseinzadeh, S.; Aliehyaei, M.; Makkeh, S.A.; Astiaso Garcia, D. Renewable energy desalination; a sustainable approach for water scarcity in arid lands. Int. J. Sustain. Eng. 2021, 14, 1-27. [CrossRef]

3. Ahmadi, M.H.; Ghazvini, M.; Sadeghzadeh, M.; Nazari, M.A.; Kumar, R.; Naeimi, A.; Ming, T. Solar power technology for electricity generation: A critical review. Energy Sci. Eng. 2018, 6, 340-361. [CrossRef]

4. Kurtz, S.; Haegel, N.; Sinton, R.; Margolis, R. A new era for solar. Nat. Photonics 2017, 11, 3-5. [CrossRef]

5. Urraca, R.; Huld, T.; Lindfors, A.V.; Riihelä, A.; Martínez-De-Pisón, F.; Sanz-García, A. Quantifying the amplified bias of PV system simulations due to uncertainties in solar radiation estimates. Sol. Energy 2018, 176, 663-677. [CrossRef]

6. Mayhoub, M.; Carter, D. Methods to estimate global and diffused luminous efficacies based on satellite data. Sol. Energy 2011, 85, 2940-2952. [CrossRef]

7. Camilo, F.; Castro, R.; Almeida, M.; Pires, V.F. Economic assessment of residential PV systems with self-consumption and storage in Portugal. Sol. Energy 2017, 150, 353-362. [CrossRef]

8. Huld, T.; Salis, E.; Pozza, A.; Herrmann, W.; Müllejans, H. Photovoltaic energy rating data sets for Europe. Sol. Energy 2016, 133, 349-362. [CrossRef]

9. Rashid, M.S.R.B.M.; Zheng, J.; Sng, E.; Rajendhiran, K.M.; Ye, Z.; Lim, L.H.I. An enhanced cloud segmentation algorithm for accurate irradiance forecasting. Sol. Energy 2021, 221, 218-231. [CrossRef]

10. Khatibi, A.; Astaraei, F.R.; Ahmadi, M.H. Generation and combination of the solar cells: A current model review. Energy Sci. Eng. 2019, 7, 305-322. [CrossRef]

11. Hansen, C.W.; Martin, C.E. Photovoltaic System Modeling Uncertainty and Sensitivity Analyses; Office of Scientific and Technical Information (OSTI): Oak Ridge, TN, USA, 2015; p. 82. 
12. Calcabrini, A.; Weegink, R.; Manganiello, P.; Zeman, M.; Isabella, O. Simulation study of the electrical yield of various PV module topologies in partially shaded urban scenarios. Sol. Energy 2021, 225, 726-733. [CrossRef]

13. Goss, B.; Gottschalg, R.; Betts, T. Uncertainty Analysis of Photovoltaic Energy Yield Prediction. 2012. Available online: https: / / www.semanticscholar.org/paper/Uncertainty-analysis-of-photovoltaic-energy-yield-Goss-Gottschalg/b99cdaa170 6bc1de6084c8a415d22caff48be0a5\#paper-header (accessed on 5 October 2021).

14. Müller, B.; Hardt, L.; Armbruster, A.; Kiefer, K.; Reise, C. Yield predictions for photovoltaic power plants: Empirical validation, recent advances and remaining uncertainties. Prog. Photovolt. Res. Appl. 2016, 24, 570-583. [CrossRef]

15. Dirnberger, D.; Müller, B.; Reise, C. PV module energy rating: Opportunities and limitations. Prog. Photovolt. Res. Appl. 2015, 23, 1754-1770. [CrossRef]

16. Huld, T.; Amillo, A.M.G. Estimating PV Module Performance over Large Geographical Regions: The Role of Irradiance, Air Temperature, Wind Speed and Solar Spectrum. Energies 2015, 8, 5159-5181. [CrossRef]

17. Cole, I.; Palmer, D.; Goss, B.; Koubli, E.; Betts, T.; Thomson, M.; Gottschalg, R. Impact Analysis of Irradiance Dataset Selection on Photovoltaic System Energy Yield Modelling. In Proceedings of the 1st International Conference on Large-Scale Grid Integration of Renewable Energy, New Delhi, India, 6-8 September 2017.

18. Kaaya, I.; Ascencio-Vásquez, J.; Weiss, K.-A.; Topič, M. Assessment of uncertainties and variations in PV modules degradation rates and lifetime predictions using physical models. Sol. Energy 2021, 218, 354-367. [CrossRef]

19. Carrillo, J.M.; Martínez-Moreno, F.; Lorenzo, C.; Lorenzo, E. Uncertainties on the outdoor characterization of PV modules and the calibration of reference modules. Sol. Energy 2017, 155, 880-892. [CrossRef]

20. Urraca, R.; Huld, T.; Martínez-De-Pisón, F.; Sanz-Garcia, A. Sources of uncertainty in annual global horizontal irradiance data. Sol. Energy 2018, 170, 873-884. [CrossRef]

21. Aramesh, M.; Pourfayaz, F.; Haghir, M.; Kasaeian, A.; Ahmadi, M.H. Investigating the effect of using nanofluids on the performance of a double-effect absorption refrigeration cycle combined with a solar collector. Proc. Inst. Mech. Eng. Part A J. Power Energy 2019, 234, 981-993. [CrossRef]

22. Abdollahpour, A.; Ghasempour, R.; Kasaeian, A.; Ahmadi, M.H. Exergoeconomic analysis and optimization of a transcritical CO2 power cycle driven by solar energy based on nanofluid with liquefied natural gas as its heat sink. J. Therm. Anal. Calorim. 2019, 139, 451-473. [CrossRef]

23. Vakilabadi, M.A.; Bidi, M.; Najafi, A.F.; Ahmadi, M.H. Energy, Exergy analysis and performance evaluation of a vacuum evaporator for solar thermal power plant Zero Liquid Discharge Systems. J. Therm. Anal. Calorim. 2019, 139, 1275-1290. [CrossRef]

24. Naseri, A.; Bidi, M.; Ahmadi, M.H.; Saidur, R. Exergy analysis of a hydrogen and water production process by a solar-driven transcritical $\mathrm{CO}_{2}$ power cycle with Stirling engine. J. Clean. Prod. 2017, 158, 165-181. [CrossRef]

25. Hiendro, A.; Kurnianto, R.; Rajagukguk, M.; Simanjuntak, Y.M. Junaidi Techno-economic analysis of photovoltaic/wind hybrid system for onshore/remote area in Indonesia. Energy 2013, 59, 652-657. [CrossRef]

26. Ashtiani, M.N.; Toopshekan, A.; Astaraei, F.R.; Yousefi, H.; Maleki, A. Techno-economic analysis of a grid-connected PV/battery system using the teaching-learning-based optimization algorithm. Sol. Energy 2020, 203, 69-82. [CrossRef]

27. Suhane, P.; Rangnekar, S.; Mittal, A.; Khare, A. Sizing and performance analysis of standalone wind-photovoltaic based hybrid energy system using ant colony optimisation. IET Renew. Power Gener. 2016, 10, 964-972. [CrossRef]

28. Ren, H.; Wu, Q.; Gao, W.; Zhou, W. Optimal operation of a grid-connected hybrid PV/fuel cell/battery energy system for residential applications. Energy 2016, 113, 702-712. [CrossRef]

29. Ahmadi, S.; Abdi, S. Application of the Hybrid Big Bang-Big Crunch algorithm for optimal sizing of a stand-alone hybrid PV/wind/battery system. Sol. Energy 2016, 134, 366-374. [CrossRef]

30. Aguilar, F.; Crespí-Llorens, D.; Vicente-Quiles, P. Techno-economic analysis of an air conditioning heat pump powered by photovoltaic panels and the grid. Sol. Energy 2019, 180, 169-179. [CrossRef]

31. Emmanuel, M.; Akinyele, D.; Rayudu, R. Techno-economic analysis of a $10 \mathrm{kWp}$ utility interactive photovoltaic system at Maungaraki school, Wellington, New Zealand. Energy 2017, 120, 573-583. [CrossRef]

32. Adaramola, M.S. Viability of grid-connected solar PV energy system in Jos, Nigeria. Int. J. Electr. Power Energy Syst. 2014, 61, 64-69. [CrossRef]

33. Mondal, M.A.H.; Islam, A.S. Potential and viability of grid-connected solar PV system in Bangladesh. Renew. Energy 2011, 36, 1869-1874. [CrossRef]

34. El-Shimy, M. Viability analysis of PV power plants in Egypt. Renew. Energy 2009, 34, 2187-2196. [CrossRef]

35. Adaramola, M.S. Techno-economic analysis of a $2.1 \mathrm{~kW}$ rooftop photovoltaic-grid-tied system based on actual performance. Energy Convers. Manag. 2015, 101, 85-93. [CrossRef]

36. Edalati, S.; Ameri, M.; Iranmanesh, M.; Tarmahi, H.; Gholampour, M. Technical and economic assessments of grid-connected photovoltaic power plants: Iran case study. Energy 2016, 114, 923-934. [CrossRef]

37. Li, M.; Ji, X.; Li, G.; Yang, Z.; Wei, S.; Wang, L. Performance investigation and optimization of the Trough Concentrating Photovoltaic/Thermal system. Sol. Energy 2011, 85, 1028-1034. [CrossRef]

38. Stine, W.B.; Geyer, M. Power from the Sun. Available online: https:/ /www.powerfromthesun.net/ (accessed on 23 April 2020).

39. Wei, X.; Lu, Z.; Wang, Z.; Yu, W.; Zhang, H.; Yao, Z. A new method for the design of the heliostat field layout for solar tower power plant. Renew. Energy 2010, 35, 1970-1975. [CrossRef] 
40. Duffie, J.A.; Beckman, W.A. Solar Engineering of Thermal Processes; Wiley: Hoboken, NJ, USA, 2013; pp. 12-20.

41. Feldman, D.; Ramasamy, V.; Fu, R.; Ramdas, A.; Desai, J.; Margolis, R. U.S. Solar Photovoltaic System and Energy Storage Cost Benchmark: Q1 2020. Available online: https://www.nrel.gov/news/program/2021/documenting-a-decade-of-cost-declinesfor-pv-systems.html (accessed on 5 October 2021). 